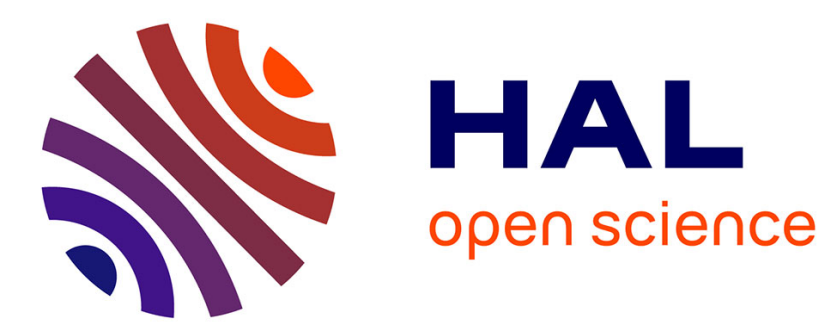

\title{
Integrated Energy Value Analysis: A New Approach
}

L. Bettoni, L. Mazzoldi, I. Ferretti, L. Zavanella, S. Zanoni

\section{To cite this version:}

L. Bettoni, L. Mazzoldi, I. Ferretti, L. Zavanella, S. Zanoni. Integrated Energy Value Analysis: A New Approach. IFIP International Conference on Advances in Production Management Systems (APMS), Sep 2015, Tokyo, Japan. pp.670-679, 10.1007/978-3-319-22756-6_82 . hal-01417633

\section{HAL Id: hal-01417633 \\ https://hal.science/hal-01417633}

Submitted on 15 Dec 2016

HAL is a multi-disciplinary open access archive for the deposit and dissemination of scientific research documents, whether they are published or not. The documents may come from teaching and research institutions in France or abroad, or from public or private research centers.
L'archive ouverte pluridisciplinaire HAL, est destinée au dépôt et à la diffusion de documents scientifiques de niveau recherche, publiés ou non, émanant des établissements d'enseignement et de recherche français ou étrangers, des laboratoires publics ou privés.

\section{(c)(1)}

Distributed under a Creative Commons Attribution| 4.0 International License 


\title{
Integrated Energy Value Analysis: a new approach
}

\author{
L.Bettoni, L.Mazzoldi, I.Ferretti, L.Zavanella, S.Zanoni \\ University of Brescia, Department of Industrial Engineering, \\ Via Branze 38, I-25123 Brescia, Italy \\ 1.bettoni@unibs.it, laura.mazzoldi@unibs.it,ivan.ferretti@unibs.it, \\ lucio.zavanella@unibs.it, simone.zanoni@unibs.it
}

\begin{abstract}
The improvement of energy efficiency of $20 \%$ is one of the three objectives of the EU Directive 20-20-20. To reach this goal, all production processes have to be analysed with reference to their energy consumption so as to identify actions aimed at removing or reducing energy wastes. From the Lean Production framework, the variation of the Value Stream Mapping (VSM), the Energy VSM (EVSM) is selected as a useful tool able to highlight the seven types of wastes identified by Ohno in Toyota Production System and energy wastes. This work aims at proposing a possible modification of the EVSM, which encompasses it within the Energy Audit and the Energy Balance Chart. The goal is to realize a deep energy analysis, highlighting energy wastes, in order to understand which corrective actions must be implemented or which corrections to energy reduction should be considered to reduce energy wastes.
\end{abstract}

Keywords: Energy Flow, Energy Analysis, Energy Value Stream, Energy Audit, Lean and Energy.

\section{Introduction}

The study of energy consumption and costs in energy intensive sectors is of primary importance, because of the increase in energy price and its related environmental concerns. In literature, Energy issue is a wide topic, so it is faced from different point of view. Summarizing some of these, we want to highlight the magnitude of energy subject. Some studies have focused on the assessment models of energy consumptions of the system considered, which have the purpose to collect energy data allowing to highlight highest energy consumption process or equipment and quantitatively evaluate energy losses of an industry process [1-3]. Other studies deal with the measurement of the on-time energy consumptions, in order to straightaway solve different energy-decision problem, and on the solution of multi-objective energy problem related to energy policies, energy operations and management. As the survey in [4], which states that the Decision Analysis (DA) is largely applied to analyze Energy and Environmental (E\&E) issues. Different researches are focalized on energy management system [5] or on technological solutions for reducing energy consumption and improving energy efficiency, in comparison with BATs (Best Available Techniques) 
standards, even if there is a poor knowledge of BATs [6-7]. Energy intensive companies needs to identify all type of energy use in their processes, to divide which type of energy use is necessary for the production and which is removable (waste). All energy use, which is not strictly necessary for the production, is a cost that the customer is not willing to pay for. For this reason is necessary to provide to the energy intensive companies a useful tool which allows identifying this type of energy use. Even though there are lot contributions in literature, we observed a lack in the availability of an energy analysis able to bring out the different type of energy use. The objective of the Integrated Energy Analysis is to analyse energy use from a top down approach. This approach allows identifying at first macro-evidences of energy use and waste, and gradually highlighting how energy use and wastes are strictly related to production and logistical issues. This research is focused on tools able to identify and quantify energy consumption, waste, energy value and flow in an energy intensive production process. This study, highlighting energy wastes and anomalies and integrating tools derived from Energy and Lean analysis, proposes a new approach (named Integrated Energy Value Analysis) for the analysis of energy features of a production system. Related to other energy analysis, in this research the type of energy waste is pointed out. This information is important to identify the exact action to improve to reduce or remove it. The reduction of wastes is the main objective of Lean production, which aims at reducing costs, improving process flow and reducing lead times, to meet customer expectations and improve environmental quality and in order to achieve competitiveness. To apply the five tenets of Lean production, it is necessary to remove or at least reduce wastes "Whenever there is a product (or service) for a customer, there is a value stream. The challenge lies in seeing it" [9]. Therefore, to see the value stream of a product through the production process, a tool has been developed: the Value Stream Mapping (VSM). VSM is a suitable tool for waste identification and their subsequent elimination (or almost reduction), thanks to its graphical appeal. Some scientific works, as Erlach [10], face the issue of directly evaluating energy efficiency into Lean approach. Erlach introduces the energy contribution in the VSM including energy indicators such as Energy Intensity and Energy Density into the process box. Moreover, he defines eight design guidelines to derive measures for energy efficiency increase. Bogdanski [11] proposes an extended energy value stream approach, which introduces three innovative characteristics. The main novel feature is the introduction of the state of the machines, classified as ramp-up, processing and idle. For each state the measurement of power and time are collected, in order to consider dynamic energy profile. The second feature is the consideration of energy consumption of technical building service. The third distinction of the extended EVSM is the consideration of product related issues as technological characteristics and design. Another guideline about energy improvement through Energy Value Stream Analysis is the approach of the "Lean and Energy Toolkit", published by U.S. Environmental Protection Agency [12]. Efforts on Energy Value Stream Mapping are needed.

The remainder of the paper is organized as follows: in section 2, the Integrated Energy Value Analysis methodology is introduced. In section 2.1, the proposed Energy Audit approach is presented; the Energy Value Stream Mapping is explored in section 2.3 and in section 2.4 the Energy Balance Chart is studied in depth. The Future State 
is described in section 4. The conclusions and further developments are summarized in section 5 .

\section{The Methodology}

The Integrated Energy Value Analysis (IEVA) is an integration of tools for the energy consumption assessment of an energy intensive process. The focus is on energy issues, so logistical performances are not encompassed by energy analysis and considerations.

Next to the seven wastes identified by Ohno [8], during the years researchers added some other wastes, considering different features of the system investigated and the need and criticism to the system itself, i.e. applying Lean and VSM to the service companies [13]. Power and energy are considered as additional wastes, but in the Integrated Energy Value Analysis, energy is the topic of the research. The IEVA analyses different kinds of energy consumptions (and wastes) related, e.g., to the state of the machines or the synchronization of the resources. The objective of the IEVA is to find the hidden energy wastes existing in the production process in order to remove, if possible, or reduce them by energy scheduling models.

Thanks to the analysis of the energy consumption of the machines, different states corresponding to different power levels are observed. In the production state, the machine produces and the power is consistent with the production effort. In the holding state, the machine doesn't produce, but the item newly worked out has not yet been released (i.e., the power is lower than in the production state, as the machine simply holds the item). In the idle state, the lowest power level, the machine is turned on but it is neither producing any items (i.e. no items are in process) nor holding them: nevertheless, some energy is still consumed due to auxiliary equipment of machines, which must be kept in function.

As for the VSM, the energy consumption can be Value-Added, (VA), Non ValueAdded (NVA) and Necessary but NVA (NbNVA).

We identified different definitions of "energy waste". (a) When it is possible to consume less energy to produce the same output (i.e. quantity of produced products). (b) When energy is employed for NVA and NbNVA activities. And finally, (c) when energy is consumed supporting Lean thinking wastes, i.e. energy consumed for defective products, energy consumed for useless transportation, energy consumed for extra processing, defective production.

The IEVA focuses its attention on the first two definitions of energy wastes, i.e. (a) and (b), because the other ones are reduced or removed acting on Lean wastes. Thus, the energy wastes, which the IEVA focuses on, are:

- Energy consumption during Idle State (i.e. during the set-up),

- Energy consumption during Holding State,

- Energy Consumption for Overproduction,

- Energy lost for lack of Synchronization between energy-consuming resources and their associated auxiliary services.

The objective of the investigation is to create an "as is" analysis in order to verify energy consumptions, energy costs and energy wastes. The goal is to reduce both 
energy consumptions and costs, optimizing energy management, producing more products and consuming less energy, thus becoming "energy efficient". The IEVA allows the identification of energy wastes in order to find corrective actions able to remove or reduce them. The first step is to implement an Energy Audit, distinguishing processes and services resources and classifying resources as Value Added, Non Value Added and Necessary but Non Value Added. The second steps is to create the Energy Value Stream Mapping with related Energy Lines and study the wastes at each single resource (EVA-ENVA); study the synchronization between resources and related auxiliary services (vertical analysis - focus on the single machine). The last step is to create the Energy Balance Chart in order to compare takt time and energy consumption for those process resources, which are more energy consuming. At the end analyses the EBC in order to define an energy scheduling model suitable for the energy wastes reduction, considering the production time value (under/over takt time). In the following sections, the tools are analysed in detail.

\subsection{Energy Audit}

As first step of the IEVA methodology, the Energy Audit (EA) is performed. This technique uses the Lean organization approach in order to look for wastes in the energy use. The philosophy underlying this approach is based on the understanding of how energy is used in a particular process in order to discriminate what is strictly necessary (Value Added) and what can be improved (reduction or elimination of Non Value Added). The phases of the project can be summarized in (1) Energy Analysis, (2) Management analysis and finally (3) Root cause.

During the first phase the data of energy consumption (i.e., rated power, hours of operation per year, estimate of load and contemporary factors and efficiency) are collected and the consumptions at the resources are divided between electrical and thermal loads, with the aim of reconstructing the energy consumptions and costs, reporting a yearly energy balance. The energy balance allows the user to appreciate the annual energy consumption at each user (resource) and a Pareto analysis can be performed to identify the more expensive utilities in the energy perspective.

The Management analysis allows the management to identify system bottlenecks, by the analysis of production processes and the estimation of lead times, thus establishing the actual production rate of the system. The comparison between this value and the production capacity at each station within the process allows the identification of the non-utilized production capacity at the different stations as compared to the bottleneck. This assessment is very important because energy cost, as many other types of cost, can be divided into a fixed component and a variable component, and such components can be identified thanks to this specific activity. Moreover, the resources of the system are further classified as VA and NVA, by the analysis of the states of the machines (production state, holding state and idle state).

Finally, during the last phase of EA, technological improvements are identified and prioritized thanks to the Root cause analysis, which allows us to verify any possible improvement actions, understanding the motivations that underlie the costs currently incurred by the company. 


\subsection{Energy Value Stream Mapping}

The EVSM is structured into three sections, as presented in Fig. 1: the Process of production flow (at the top), the Auxiliary service flows (in the middle) and the Energy lines (in the bottom). The EVSM is configured as a particular modification of the traditional VSM: changes are implemented in order to focus only on energy. In the process box of the EVSM, different values are specified: the energy consumption during production, the energy consumption during holding time and the uptime, i.e. the idle time of the process. All auxiliary services necessary for the production are shown in another process box, under the main process stream, and once again energy consumption and uptime are specified.

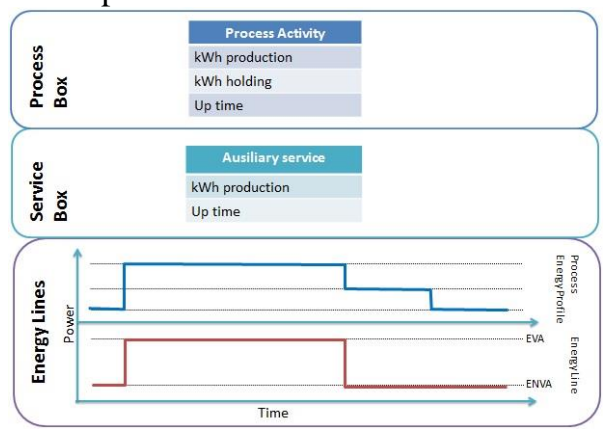

Fig. 1. EVSM configuration.

In the IEVA, instead of visualizing the time line, the Energy Lines is shown, distinguishing an energy value added line, EVA, (for the production state) and energy non value-added lines, ENVA (for the holding and idle states). Using this configuration, two analyses can be carried out, in order to obtain two kinds of outputs: (1) Identification of single resource's wastes: the inefficiencies of the single resource are analysed and (2) Identification of wastes related to the synchronization between process resource and related auxiliary service, which works together. Once the removable inefficiencies have been identified (so ENVA), this tool allows the user to define corrective action plans which enable to create the Future State. Fig. 2. EVSM and Energy Line

Fig. 3. shows an example of the energy profile of a resource which changes its state over time.

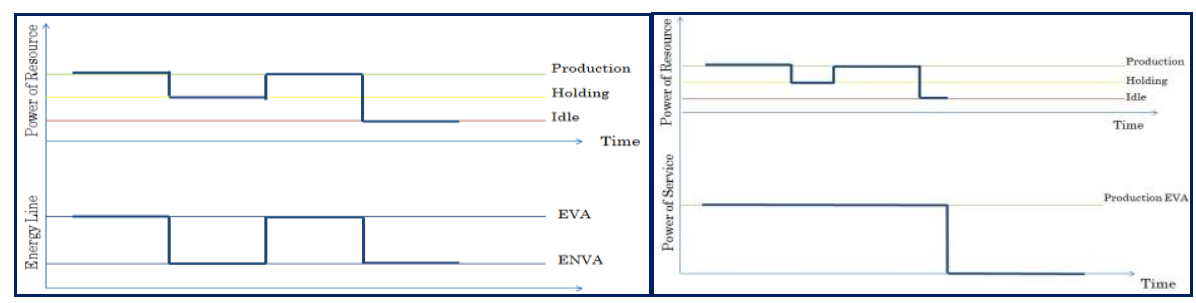

Fig. 2. EVSM and Energy Line

Synchronism

Fig. 3. Example of a waste for lack of

In the EVSM, as well as the traditional VSM, the Future State shows the goals the company aims at in the future, i.e. the energy consumption has to be reduced during the holding and idle states, which are ENVA, with respect to the Current State. The most suitable method that can be applied to reduce holding and idle times has to be 
investigated using energy scheduling models, the development of which is not in the aim of this work.

The second analysis, allowed by the EVSM, includes both kinds of resources: process resource and auxiliary service resource. The aim is to verify whether the auxiliary service resource is synchronized with its associated process resource or not. Often, in companies it is observed that the auxiliary service resource (for example, the fun) is in function even if it is not necessary for the associated process resource (for example the furnace), which is, e.g., in its holding state (or in its idle state). In this case the resources are not synchronized, Fig. , and an energy waste is present.

A possible Future State would be that the auxiliary service is turned off (or set to a minimum power level) when the process resource doesn't need it.

\subsection{Energy Balance Chart}

Another tool, derived from the VSM, is used during the Current State definition step, in order to identify other kinds of wastes and to determine the optimal configuration of the Future State: such a tool is the Balance Chart (BC). In the traditional BC, once defined the Takt Time, production times at all the resources (machines or operators or the production times to produce different products in a single machine) are pointed out, in order to identify the bottleneck of the system. Once located the bottleneck (which identifies a type of waste, as it breaks off the flow of the value at takt time), Lean thinking provides some solutions based on system's features, aiming at balancing the flow of the production mix. Thus, the $\mathrm{BC}$ allows the analysis of the Current State situation, highlighting the takt time, the resource production time, which has to be lower than the takt time, and the bottleneck of the system, for which the production time is higher than the takt time. In the energy perspective, there isn't an indicator suitable for quantifying how much energy is needed to define an energy efficient system and, at the same time, to maintain the logistic performances linked to the takt time. Therefore, the objective is to find the optimal (i.e. the minimum) energy consumption, in order to comply with both the takt time and the due date required by the customer. To build up an Energy Balance Chart it is necessary to analyze the energy consumption for the current cycle time, for that process resource that is more energy consuming. In order to find the cycle time that ensures the minimum energy consumption, the Total Energy function has to be minimized. The optimum found is the indicator that quantify how much energy is needed at the resource, maintaining the logistical performance. If it is possible to act on the production times of the machines, the Energy Balance Chart helps to highlight the energy behaviour of machines themselves and to identify the optimal production and holding times to reduce energy wastes. As for the traditional Operation Machine Production Balance Chart, the operation machine production time may be lower or higher than the takt time.

To carry out the analysis, we consider one resource or machine (M1): two different cases related to production times may be defined: (1) production time under takt time and (2) over takt time. The following machine, namely M2, which has to be replenished by $\mathrm{M} 1$, on the contrary, it runs at the takt time and there is no intermediate buffer between the two machines. So, in the first case (under takt time) the machine M1, once ended the production of the current item, stays in the holding state till the fol- 
lowing machine becomes available to receive the item itself, i.e. till the takt time. In the second, M1 finishes the production later than the job completion by machine M2, which has to stay in idle state from the end of its production time (i.e. takt time) till M1 finishes to produce its item. The analysis is carried out in order to find the minimum energy consumption related to machine M1.

We assume that the production rate is variable, and that the energy consumption for production can be described as a convex function of the production time, while energy consumption for holding, on the other hand, decreases linearly when increasing the production time, i.e. it is proportional to the holding time.

Let us introduce the following notation in order to define the mathematical functions of energy consumption for production and holding states:

$t t:$ takt time [time unit];

$t p$ : production time of the resource [time unit];

$t h$ : holding time of the resource [time unit], defined as: $t p, t h=t t-t p$

$\alpha, \beta, \gamma:$ coefficients of energy consumption for production function;

$\delta$ : coefficient of energy consumption for holding function;

$W p$ : power required for production $[\mathrm{kW}]$;

$W h$ : power required for holding $[\mathrm{kW}]$;

We also assume that the energy consumption for production, Ep, is a function of the production time, as in [14] by:

$$
E p(t p)=W p \cdot\left(\alpha \cdot t p^{2}-\beta \cdot t p+\gamma\right),
$$

while the energy consumption for holding, $E h$, is defined by:

$$
E h(t h)=W h \cdot \delta \cdot(t t-t p) \text { when } t h>0,0 \text { oherwise. }
$$

The holding energy consumption is proportional to the holding time and decrease linearly increasing production time.

The Total Energy Consumption is the summation of energy consumption for production, $E p$, and energy consumption for holding, $E h$, and it is expressed by:

$$
\operatorname{Etot}(t p)=W p \cdot\left(\alpha \cdot t p^{2}-\beta \cdot t p+\gamma\right)+W h \cdot \delta \cdot(t t-t p) \text {. }
$$

The energy consumed when the resource runs at takt time is defined as:

$$
\text { Etakt }=\operatorname{Etot}(t p) \text { when } t p<t t \text {,Etakt }=E p(t t) \text { otherwise . }
$$

The optimal combination of production time and holding time, which minimizes energy consumption, can be found by setting the first derivative of the total energy consumption function to zero, from which the optimal production time that minimizes energy consumption is derived as:

$$
t p^{*}=\frac{W p \cdot \beta+W h \cdot \delta}{2 \cdot W p \cdot \alpha} .
$$

The optimal production time $t p^{*}$ is determined for the resources studied, i.e. the production time that minimizes the Etot, Fig. . Consequently, the optimal configuration of production time/holding time is defined, too. So the Energy Balance Chart (EBC), Fig. , can be drawn for different energy configurations, in order to compare the Current State of the resource studied and to determine the optimal configuration. 


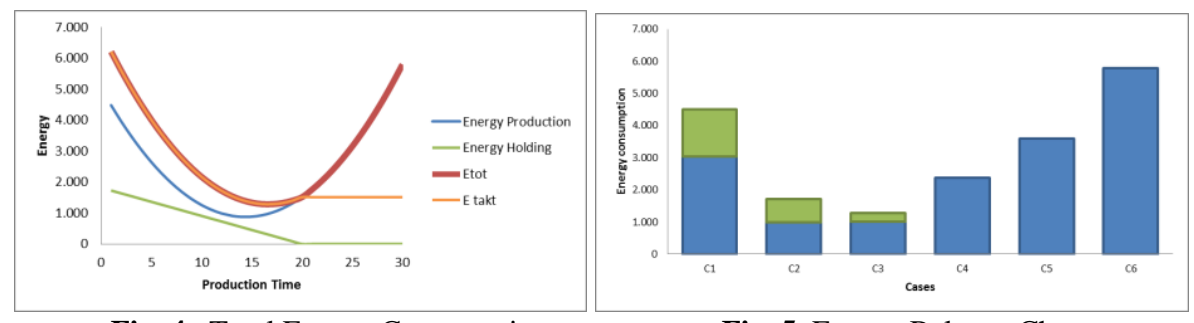

Fig. 4. Total Energy Consumption

Fig. 5. Energy Balance Chart

The EBC shows the distribution of energy consumptions for different production time values. Thanks to the EBC, it is possible to compare the current Total Energy Consumption with the minimum Total Energy Consumption, which represents the goal to be reached to become "energy efficient". It has to be noted that the EBC identifies the optimal energy trade-off between energy consumption for production and holding. In this study the logistic costs are not considered, so a trade-off between energy savings and logistic costs should be deeply investigated using additional analyses, i.e. energy scheduling models.

\section{Future State}

Once defined the energy consumption of the resources and the associated auxiliary services, through the Current State, it is possible to identify the areas of improvement, both management and technological. The type of corrective actions have to be investigated through different models, as the energy scheduling model. Once the results have been achieved from the Energy Value Stream Mapping and the Energy Balance Chart, thus determining the optimal solution, these tools can be revisited in order to edit and improve the Future State, as well as to highlight the energy goal of the system.

\section{Conclusion}

The proposed Integrated Energy Value Analysis (IEVA) is a method that allows the managers to investigate energy wastes at different levels of analysis. The Energy Audit, the Energy Value Stream and the Energy Balance Chart are the tools used to perform the IEVA. For the energy consuming resources, different states are classified (production, holding, idle) and each state is categorized as Energy Value Added or Energy Non Value Added. The evaluation of energy consumption is carried out for each single resource to analyze energy use during different states, and for the synchronisation of both resources and associated auxiliary services to highlight the hidden energy wasted because of the incorrect management of resources. The Energy Balance Chart, which allows to relate takt time and energy consumption, in order to understand the optimal energy scheduling model to apply so as to reduce energy consumption. Possible further developments of the present study are the introduction of energy quantitative and qualitative performance measures, in order to control the energy performances, as well as logistical ones. Finally, the definition of a methodol- 
ogy aimed at selecting the optimal energy scheduling model to be applied has still to be studied in deep.

\section{References}

[1] Yi-Ming Wei, Hua Liao, Ying Fan, 2007. An empirical analysis of energy efficiency in China's iron and steel sector. Energy 32, 2262-2270.

[2] R. Saidur, N.A.Rahim, H.H.Masjuki, S.Mekhilef, H.W.Ping, M.F.Jamaluddin, 2009, End-use energy analysis in the Malaysian industrial sector. Energy, 34, 153-158.

[3] G.-B. Hong et al., 2011, Energy flow analysis in pulp and paper industry. Energy 36, 3063-3068.

[4] P. Zhou, B.W. Ang, K.L. Poh, 2006, Decision analysis in energy and environmental modeling: An update. Energy, 31, 2604-2622.

[5] Seyithan Ahmet Ates, Numan M. Durakbasa, 2012, Evaluation of corporate energy management practice of energy intensive industries in Turkey. Energy, 45,81-91.

[6] European Commission - Integrated Pollution Prevention and Control (IPPC) (2008). Reference document on best available techniques for energy efficiency.

[7] D. Saygin, E. Worrell, M.K. Patel, D.J. Gielen , 2011, Benchmarking the energy use of energy-intensive industries in industrialized and in developing countries. Energy,36, 6661-6673.

[8] Womack J.P., Jones D.T., 1996. Lean Thinking: Banish Waste and Create Wealth in Your Corporation. New York: Simon \& Schuster.

[9] Rother, M., Shook, J., 1999. Learning to See: Value Stream Mapping to Add Value and Eliminate Muda. The Lean Enterprise Institute, Inc., Brookline, MA.

[10] Erlach, K. (2010). Energy Efficiency in Manufacturing Using the Energy Value Stream Method for Building an Energy-Efficient Factory. Proceedings of APMS 2010 International Conference. Cernobbio, Como, ITA.

[11] Bogdanski G., Schönemann M., Thiede S., Andrew S., Herrmann C., 2012. An Extended Energy Value Stream Approach Applied on the Electronics Industry.Proceedings of APMS 2012 International Conference.

[12] EPA (2007). The Lean and Energy Toolkit. U.S. Environmental Protection Agency. http://www.epa.gov/lean/toolkit/LeanEnergyToolkit.pdf.

[13] Pavnaskar S. J., Gershenson J. K., Jambekar A. B., 2003. Classification scheme for lean manufacturing tools. International Journal of Production Resource, vol. 41, no. 13, 3075-3090

[14]Lixin Tang, Ping Che, Jiyin Liu, 2012. A stochastic production planning problem with nonlinear cost. Computers \& Operations Research, vol. 39, 1977-19877. 